\title{
Geographic disparities of asthma prevalence in south-western United States of America
}

\author{
Lung-Chang Chien ${ }^{1,2}$, Hasanat Alamgir ${ }^{3}$ \\ ${ }^{1}$ Department of Biostatistics, University of Texas School of Public Health at San Antonio Regional Campus, San \\ Antonio, USA; ${ }^{2}$ The Research of Advance Community Health Center, University of Texas Health Science Center \\ at San Antonio Regional Campus, San Antonio, USA; ${ }^{3}$ Department of Epidemiology, Human Genetics \& \\ Environmental Sciences, University of Texas School of Public Health at San Antonio Regional Campus, San \\ Antonio, USA
}

\begin{abstract}
Asthma is one of the most prevalent chronic diseases in the United States of America (USA), and many of its risk factors have so far been investigated and identified; however, evidence is limited on how spatial disparities impact the disease. The purpose of this study was to provide scientific evidence on the location influence on asthma in the four states of southwestern USA (California, Arizona, New Mexico and Texas) which, together, include 360 counties. The Behavioral Risk Factor Surveillance System database for these four states covering the period of 2000 to 2011 was used in this analysis, and a Bayesian structured additive regression model was applied to analyse by a geographical information system. After adjusting for individual characteristics, socioeconomic status and health behaviour, this study found higher odds associated with asthma and a likely cluster around the Bay Area in California, while lower odds appeared in several counties around the larger cities of Texas, such as Dallas, Houston and San Antonio. The significance map shows 43 of 360 counties (11.9\%) to be high-risk areas for asthma. The level of geographical disparities demonstrates that the county risk of asthma prevalence varies significantly and can be about $19.9 \%$ (95\% confidence interval: 15.3-25.8) higher or lower than the overall asthma prevalence. We provide an efficient method to utilise and interpret the existing surveillance data on asthma. Visualisation by maps may help deliver future interventions on targeted areas and vulnerable populations to reduce geographical disparities in the burden of asthma.
\end{abstract}

Keywords: asthma, geographical disparities, prevalence, spatio-temporal analysis, United States of America.

\section{Introduction}

Asthma is a chronic lung disease that inflames and narrows the airways. Common symptoms include wheezing, coughing, chest tightness and shortness of breath. People who have asthma tend to react strongly to certain inhaled substances (PubMed Health, 2013). Asthma is one of the most prevalent chronic diseases and an increasing health concern in the United States of America (USA). In 2010, 18.7 million adults (one in 12) and 7 million children (one in 11) suffered from asthma according to the Centers for Disease Control and Prevention (CDC, 2012). In the recent decade, the proportion of people in USA with asthma grew by $15 \%$ (CDC, 2012). Asthma results in

Corresponding author:

Hasanat Alamgir

Department of Epidemiology, Human Genetics \&

Environmental Sciences

University of Texas School of Public Health

San Antonio Regional Campus

7411 John Smith Drive, Suite 1100, San Antonio, TX 78229, USA

Tel. +1 210 276-9012; Fax +1 210 276-9032

E-mail: Abul.H.Alamgir@uth.tmc.edu substantial economic and social burden, not only affecting individuals with asthma, but also their family members, communities, workplaces, healthcare system and society as a whole (Arif et al., 2003; Kamble and Bharmal, 2009). In 2009, asthma was attributed to 479,300 hospitalisations, 1.9 million emergency visits, and 8.9 million visits to a doctor (CDC, 2012). Nearly one in three adults with asthma misses at least 1 day of work each year due to the disease, which translates nationally into 14.2 million days of work absences (CDC, 2012).

Previous studies have identified that among adults, women, multi-racial, Black Americans, those who did not finish high school, and those with an annual household income of US\$ 75,000 or less are more likely to experience asthma (Arif et al., 2003; CDC, 2012). In addition, smokers and obese adults are at high risk of having asthma (Arif et al., 2003). Southwestern USA (Arizona, California, New Mexico and Texas) is a large geographical area along with the Mexican border stretching almost 2,000 miles $(3,219 \mathrm{~km})$. People of Hispanic/Latino origin constitute about $17 \%$ of the national population and in the south-west comprise an even larger proportion (e.g. 
$30 \%$ in Arizona; $38 \%$ in California; $46 \%$ in New Mexico; and $38 \%$ in Texas). The disparity between the general American and the Hispanic/Latino populations with respect to socioeconomic status (SES) has been widely studied (CDC, 2004, 2013; Mead et al., 2008). Compared to the non-Hispanic White population, the Hispanic/Latino population is more likely to experience both lower income and lower educational attainment, higher language barrier, lower coverage of health insurance, and poorer housing and residential environment (Mead et al., 2008; CDC, 2013). Considering these disparities, the prevalence of asthma is expected to be higher in these states, which have large foreign-borne populations.

In 2011, CDC reported that Arizona, California, New Mexico and Texas have a greater adult lifetime and current asthma prevalence compared to the states that border Canada and non-border states (CDC, 2011a). In these states, the approximate numbers of adults with lifetime and current asthmatic problems were around 1.77 million and 1.08 million, respectively (CDC, 2011a). The Agency for Toxic Substances and Disease Registry (ATSDR) has also indicated that traffic volume, proximity to freeways, rural areas, poor quality housing and polluted environment may be associated with increased medical visits and hospitalisations for asthma (ATSDR, 2010). Despite the abundance of existing studies of asthma risk factors, the impact of geographical location has barely been studied and is still not well understood.

The Asthma State Profiles presented by CDC provides an overview of the burden of asthma in the south-western states (CDC, 2011b). Except for Arizona, for which data do not exist, a larger diversity used to appear in adult lifetime asthma prevalence measures. California had a higher rate $(13.8 \%)$ compared to the average national rate $(13.3 \%)$, but New Mexico and Texas had lower rates $(12.6 \%$ and $12.2 \%$, respectively). For current asthma prevalence, California and New Mexico have a similar rate as the national rate $(8.5 \%)$, while Texas has a much lower rate $(7.3 \%)$. These numbers reveal the existence of potential geographical disparities necessitating further investigation. Moreover, the demographic make-up and socioeconomic disadvantages present a number of challenges for the population living in these states when they suffer from asthma. Exposures, such as air pollution and factors, such as health care utilisation, have also been investigated and shown that location displays an important role among those associations (Oyana and Lwebuga-Mukasa, 2004; McEntee and Ogneva-Himmelberger, 2008; Sahsuvaroglu et al.,
2009). However, little is known about the geographical variation and disparities in prevalence of asthma, particularly in these four south-western states, which share borders to Mexico and have large Hispanic/Latino populations. Currently, most epidemiological asthma research merely present disease mapping but lack scientific evidence to quantify the impact of location.

The purpose of this study was to provide scientific evidence of geographical heterogeneity with respect to asthma prevalence within the south-western states of the USA from 2000 to 2011 using spatio-temporal analysis. We conducted an extensive literature review, which showed that no comprehensive investigation on asthma has been carried out in this region utilising complex spatial modelling for the analysis of geographical data. This study aims: (i) to demonstrate the implementation of a spatial function to estimate the association between asthma and geographical location by the use of a structured additive model; (ii) to visualise the spatial estimates in a map and convert results into meaningful explanations from public health viewpoints; (iii) to quantify geographical disparities of asthma, highlighting the level of diversity of asthma risk throughout the study area; and (iv) to calculate and map county-specific asthma prevalence by relevant and available confounder data.

\section{Materials and methods}

\section{Study area}

Including the states of Texas (254 counties), New Mexico (33 counties), Arizona (15 counties) and California (58 counties), the study covered close to $18 \%$ of the country' surface and 70 million people, almost a fourth of the total population (Fig. 1). The county was chosen as the geographical unit for performing spatial analyses, since it is the main administrative division in the country and is frequently recorded in nationwide databases like the Behavioral Risk Factor Surveillance System (BRFSS), a federally funded, annual survey system that tracks health conditions and risk behaviours since 1984. County is the earliest geographical unit of local government since the $17^{\text {th }}$ century, and it has been the main administrative division in the USA, and frequently recorded in nationwide databases. In addition, county is the smallest geographical area with the social, political, and legal responsibility for providing healthcare services in the USA (Schootman et al., 2010; US-Mexico Border Health Commission, 2013); hence, we determined to use county as the geographical 


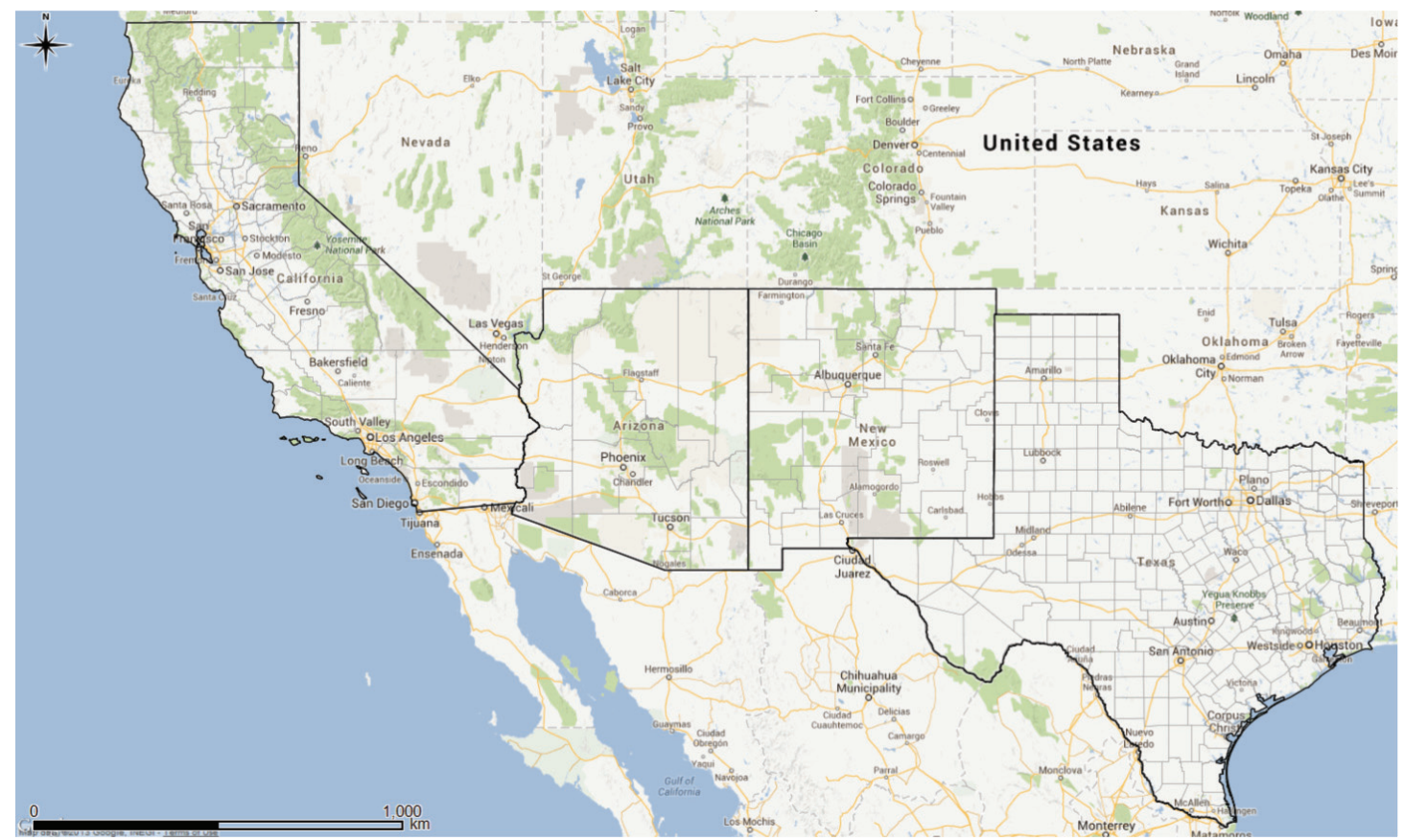

Fig. 1. Map of the south-west USA showing the states of Arizona, California, New Mexico and Texas including county borders.

unit of this study. In all, this study included 360 counties and all boundary data were retrieved from the US Census Bureau (USCB, 2013).

\section{Data source}

In order to achieve a demographically representative participant pool, the BRFSS surveys randomly select adults for telephone interview. Public and private health professionals use these survey results to identify public health problems, design policies and interventions, set goals and measure progress towards those goals. This publicly available data source provides an easily accessible opportunity to report asthma prevalence. Under the direction of CDC, BRFSS survey methods and much of the questionnaire are now standardised. Therefore, the four states in this study have the same set of variables.

\section{Study population}

The study population included survey respondents aged $\geq 18$ years living in the four south-western states from 2000 through 2011. The asthma prevalence was determined by two questions in the BRFSS survey: (a) Ever told you had asthma?; and (b) Do you still have asthma? Respondents answering yes to the first question were defined as "lifetime asthmatic", while a positive response to the second question characterised them as "currently asthmatic".

\section{Variable definitions}

The following individual characteristics among the survey respondents were analysed: state, age, race, sex, marital status and body mass index (BMI). Socioeconomic factors, such as education, income, employment status and type of health insurance (if any), were also taken into account. Smoking status, an important health index, was also included. A six-level urban and rural area factor for residential county was defined by the National Center for Health Statistics (Ingram and Franco, 2012). More details of categories in each variable are available in Table 1.

Each respondent's residence location was geocoded according to a 5-digit Federal Information Processing Standard county code, which was also used for the boundary data to implement visualization. The BRFSS database initially included a total of 347,980 respondents living in the four states. However, as respondents with unknown information on any of the variables described above (51,272 respondents) and missing county $(38,143$ respondents) were excluded, the final sample size was reduced to 267,093 .

\section{Statistical approach}

A spatiotemporal study was conducted in order to consider asthma risks, time series, and geographical information system (GIS) simultaneously. Suppose the response $Y_{i j t}$ is the asthma dummy variable, where " 1 " 
Table 1. Characteristics of respondents with respect to asthma in the south-west USA, 2000-2011.

\begin{tabular}{|c|c|c|c|c|c|}
\hline \multirow{2}{*}{ Variable } & \multicolumn{2}{|c|}{$\begin{array}{c}\text { With asthma } \\
(\mathrm{n}=34,506 ; \%=13.21)\end{array}$} & \multicolumn{2}{|c|}{$\begin{array}{c}\text { Without asthma } \\
(\mathrm{n}=226,768 ; \%=86.79)\end{array}$} & \multirow{2}{*}{$\mathrm{Pa}^{\mathrm{a}}$} \\
\hline & No. & $\%$ & No. & $\%$ & \\
\hline \multicolumn{6}{|l|}{ State } \\
\hline California & 5,639 & 16.40 & 36,124 & 15.98 & $<0.001$ \\
\hline Arizona & 12,038 & 35.01 & 74,275 & 32.85 & \\
\hline New Mexico & 7,724 & 22.46 & 51,960 & 22.98 & \\
\hline Texas & 8,982 & 26.12 & 63,711 & 28.18 & \\
\hline \multicolumn{6}{|l|}{ Race } \\
\hline White non-Hispanic & 23,277 & 67.70 & 140,812 & 62.29 & $<0.001$ \\
\hline Black non-Hispanic & 1,734 & 5.04 & 9,237 & 4.09 & \\
\hline Hispanic & 6,778 & 19.71 & 59,833 & 26.47 & \\
\hline Other non-Hispanic & 2,594 & 7.54 & 16,188 & 7.16 & \\
\hline \multicolumn{6}{|l|}{ Sex } \\
\hline Male & 11,373 & 33.08 & 94,165 & 41.65 & $<0.001$ \\
\hline Female & 23,010 & 66.92 & 131,905 & 58.35 & \\
\hline \multicolumn{6}{|l|}{ Education } \\
\hline Low (grade 8 or below) & 1,105 & 3.21 & 11,814 & 5.23 & $<0.001$ \\
\hline Middle (grades 9-12) & 9,760 & 28.39 & 69,100 & 30.57 & \\
\hline High (colleges or graduate schools) & 23,518 & 68.40 & 145,156 & 64.21 & \\
\hline \multicolumn{6}{|l|}{ Income } \\
\hline Low (sUS\$ 25,000) & 11,522 & 33.51 & 69,929 & 30.93 & $<0.001$ \\
\hline Middle (US\$ 25,001-50,000) & 8,973 & 26.10 & 61,118 & 27.03 & \\
\hline High $(\geq \operatorname{US} \$ 50,001)$ & 13,888 & 40.39 & 95,023 & 42.03 & \\
\hline \multicolumn{6}{|l|}{ Marital status } \\
\hline Married & 16,911 & 49.18 & 125,776 & 55.64 & $<0.001$ \\
\hline Never married or unmarried couple & 11,109 & 32.31 & 63,560 & 28.12 & \\
\hline Divorced, widowed or separated & 6,363 & 18.51 & 36,734 & 16.25 & \\
\hline \multicolumn{6}{|l|}{ Employment } \\
\hline Employed & 17,481 & 50.84 & 122,953 & 54.39 & $<0.001$ \\
\hline Unemployed & 16,902 & 49.16 & 103,117 & 45.61 & \\
\hline \multicolumn{6}{|l|}{ BMI } \\
\hline Underweight $(<18.50)$ & 573 & 1.67 & 4,081 & 1.81 & $<0.001$ \\
\hline Normal (18.50-24.99) & 10,865 & 31.60 & 84,972 & 37.59 & \\
\hline Overweight (25.00-29.99) & 11,617 & 33.79 & 83,134 & 36.77 & \\
\hline Obese $(\geq 30)$ & 11,328 & 32.95 & 53,883 & 23.83 & \\
\hline \multicolumn{6}{|l|}{ Smoking status } \\
\hline Current smoker & 6,082 & 17.69 & 36,560 & 16.17 & $<0.001$ \\
\hline Former smoker & 10,497 & 30.53 & 63,584 & 28.13 & \\
\hline Non smoker & 17,804 & 51.78 & 125,926 & 55.70 & \\
\hline \multicolumn{6}{|l|}{ Insurance } \\
\hline Yes & 30,273 & 88.05 & 191,572 & 84.74 & $<0.001$ \\
\hline No & 4,110 & 11.95 & 34,498 & 15.26 & \\
\hline \multicolumn{6}{|l|}{ Urban/rural area } \\
\hline Large central metro & 11,389 & 33.12 & 76,361 & 33.78 & $<0.001$ \\
\hline Large fringe metro & 3,761 & 10.94 & 23,676 & 10.47 & \\
\hline Medium metro & 7,855 & 22.85 & 49,881 & 22.06 & \\
\hline Small metro & 5,103 & 14.84 & 33,839 & 14.97 & \\
\hline Micropolitan & 5,088 & 14.80 & 34,853 & 15.42 & \\
\hline Non-core & 1,187 & 3.45 & 7,460 & 3.30 & \\
\hline \multirow{2}{*}{ Age } & Mean & SD & Mean & SD & $\mathrm{Pb}^{\mathrm{b}}$ \\
\hline & 51.39 & 16.90 & 52.35 & 17.09 & $<0.001$ \\
\hline
\end{tabular}

$\mathrm{SD}=$ standard deviation; $\mathrm{P}^{\mathrm{a}}=\mathrm{P}$-value for categorical variables was generated by the $\chi^{2}$ test $\mathrm{P}^{\mathrm{b}}=\mathrm{P}$-value for continuous age was generated by the $t$-test. 
represents people having been told that they have had asthma at some time and people currently diagnosed with asthma in contrast to people without asthma represented by " 0 ". The subscripts $(i, j, t)$ are indices representing the person, the county and the calendar year, respectively. A structured additive regression (STAR) model according to Fahrmeir and Lang (2001) was applied to build a Bayesian geoadditive logistic model framework for estimating the necessary parameters:

$$
\begin{gathered}
\operatorname{Logit}\left(\mathrm{Y}_{i j t}\right)=\log \left[\mathrm{P}\left(\mathrm{Y}_{i j t}=1\right) /\left(1-\mathrm{P}\left(\mathrm{Y}_{i j t}=1\right)\right)\right]= \\
\alpha+\beta \times \mathrm{X}+\mathrm{f}(\text { Age })+\mathrm{f}(t)+\mathrm{f}_{\text {spat }}(j)
\end{gathered}
$$

(equation 1)

where the unknown parameter $\alpha$ indicates the fixed intercept; the $\beta$ a vector of unknown parameters for the individual-level confounders $\mathrm{X}$ listed in the subsection of variable definitions. The non-linear smoothing function $\mathrm{f}(\mathrm{Age})$ is used to depict the association of asthma and continuous age from 18 to 99 year. The non-linear smoothing function $f(t)$ is defined to be used for controlling temporal autoregressive correlations over time. Two smoothing functions are B-splines with a secondorder random-walk penalty to ensure flexibility of the Gaussian errors and diffuse priors for the initial values of the age and time smoothers. The spatial function $\mathrm{f}_{\text {spat }}(j)$ is taking into account for estimating the influence of location as well as controlling spatial autocorrelations. Odds ratios (ORs) were calculated for risk factors from the exponential estimated parameters. Maps of the spatial function visualise the geographical distribution of asthma due to location, and the $95 \%$ credible interval (CI) of OR determines the significance of risk factors. More details of the STAR model's inference can be found in the Appendix.

To understand the effect of the spatial function, consider a unique OR for each county in addition to the average of all counties. Those county-level ORs calculated by the spatial function were also classified into three groups to create a significance map according to their posterior distribution with respect to 1: (i) $80 \%$ of the posterior distribution above 1 indicating a highrisk county; (ii) $80 \%$ of the posterior distribution below 1 indicating a low-risk county; and (iii) the others indicating a non-significant county (Adebayo and Fahrmeir, 2005; Kazembe and Mpeketula, 2010; Kandala et al., 2011). Geographical disparity was quantified by the equation:

$$
\left[\exp \left(\sqrt{\sigma_{\text {spat }}^{2}}\right)-1\right] \times 100 \%
$$

(equation 2) to explain the level of divergence of the county risk of asthma prevalence from the overall average. The change of geographical disparities due to risk factors was calculated by removing each risk factor, one after another.

Data managements and demographic analyses were accomplished using SAS version 9.3 (SAS Institute, 2009), and spatiotemporal analyses were carried out by R2BayesX package in $\mathrm{R}$ version 3.0.1 (Umlauf et al., 2013). All maps were generated by QGIS, a GIS that can deal with various formats such as vectors or rasters (QGIS Development Team, 2011).

\section{Results}

Table 1 compares demographic, SES and health behaviour characteristics for survey respondents with and without asthma, showing that the prevalence of asthma varied with statistical significance for each variable studied. Specifically, for demographic characteristics, respondents with asthma were more likely to be White non-Hispanic $(67.7 \%)$, female $(66.9 \%)$, highly educated $(68.4 \%)$, having relatively high income $(40.4 \%)$, married $(49.2 \%)$, employed $(50.8 \%)$, overweight $(33.8 \%)$, non-smoking $(51.8 \%)$ and covered by health insurance $(88.1 \%)$. For location, cases with asthma were more likely to live in Arizona $(35.0 \%)$ and in large central metro areas (33.1\%). Moreover, respondents with asthma were significantly younger than those without asthma. Fig. 2 visualises the geographical distribution of the county-level crude ratio for the number of respondents with asthma versus those without. Counties having greater crude asthma ratios were more likely to be located in California and Texas than in Arizona or New Mexico.

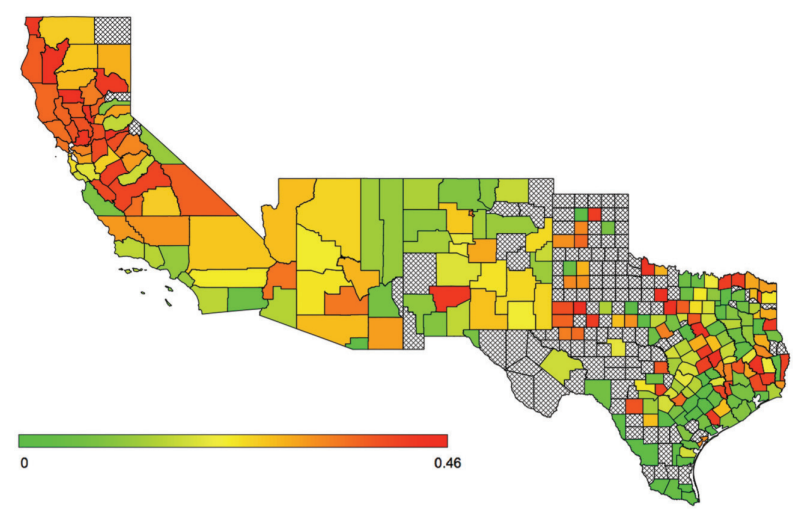

Fig. 2. County-level distribution of the crude asthma ratio in the south-west of USA, 2000-2011. 
Table 2. Odds ratios (OR) with $95 \%$ credible interval (CI) of confounders for asthma in the south-west of USA, 2000-2011.

\begin{tabular}{|c|c|c|c|}
\hline Variable & OR & $95 \% \mathrm{CI}$ & Sig. \\
\hline \multicolumn{4}{|l|}{ State } \\
\hline Arizona & 1.00 & Referent & \\
\hline California & 0.97 & $0.76 \quad 1.21$ & \\
\hline New Mexico & 1.08 & $0.88 \quad 1.30$ & \\
\hline Texas & 1.05 & $0.84 \quad 1.33$ & \\
\hline \multicolumn{4}{|l|}{ Race } \\
\hline White non-Hispanic & 1.08 & 1.031 .13 & $*$ \\
\hline Black non-Hispanic & 1.04 & $0.97 \quad 1.12$ & \\
\hline Hispanic & 0.71 & $0.68 \quad 0.75$ & $*$ \\
\hline Other non-Hispanic & 1.00 & Referent & \\
\hline \multicolumn{4}{|l|}{ Sex } \\
\hline Male & 0.69 & 0.670 .70 & $*$ \\
\hline Female & 1.00 & Referent & \\
\hline \multicolumn{4}{|l|}{ Education } \\
\hline Low (grade 8 or below) & 1.00 & Referent & \\
\hline Middle (grades 9-12) & 1.23 & $1.15 \quad 1.32$ & $*$ \\
\hline High (colleges or graduate schools) & 1.49 & 1.391 .59 & $*$ \\
\hline \multicolumn{4}{|l|}{ Income } \\
\hline Low $(\leq \mathrm{US} \$ 25,000)$ & 1.21 & 1.171 .25 & $*$ \\
\hline Middle (US\$25,001-50,000) & 1.03 & 1.001 .06 & \\
\hline High $(\geq \mathrm{US} \$ 50,001)$ & 1.00 & Referent & \\
\hline \multicolumn{4}{|l|}{ Marital status } \\
\hline Married & 1.00 & Referent & \\
\hline Never married/unmarried couple & 1.21 & $1.18 \quad 1.25$ & $*$ \\
\hline Divorced, widowed, and separated & 1.13 & 1.091 .17 & $*$ \\
\hline \multicolumn{4}{|l|}{ Employment } \\
\hline Yes & 0.84 & 0.810 .86 & $*$ \\
\hline No & 1.00 & Referent & \\
\hline \multicolumn{4}{|l|}{ Smoking status } \\
\hline Current smoker & 1.16 & 1.121 .20 & $*$ \\
\hline Former smoker & 1.20 & 1.171 .23 & $*$ \\
\hline Non smoker & 1.00 & Referent & \\
\hline \multicolumn{4}{|l|}{ BMI } \\
\hline Underweight $(<18.50)$ & 0.97 & $0.88 \quad 1.07$ & \\
\hline Normal (18.50-24.99) & 1.00 & Referent & \\
\hline Overweight (25.00-29.99) & 1.24 & 1.211 .28 & $*$ \\
\hline Obese $(\geq 30)$ & 1.78 & 1.731 .84 & $*$ \\
\hline \multicolumn{4}{|l|}{ Health insurance coverage } \\
\hline Yes & 1.37 & 1.321 .43 & $*$ \\
\hline No & 1.00 & Referent & \\
\hline \multicolumn{4}{|l|}{ Urban/rural area } \\
\hline Large central metro & 0.99 & $0.90 \quad 1.10$ & \\
\hline Large fringe metro & 0.98 & $0.88 \quad 1.09$ & \\
\hline Medium metro & 1.02 & $0.93 \quad 1.12$ & \\
\hline Small metro & 0.96 & $0.88 \quad 1.06$ & \\
\hline Micropolitan & 0.92 & $0.84 \quad 1.00$ & \\
\hline Non-core & 1.00 & Referent & \\
\hline
\end{tabular}

*Significant variables determined by the $95 \%$ CI not containing 1 .
Table 2 shows the following linear confounders with significant OR greater than 1: White nonHispanic with medium to high education, low income, never married or unmarried couple, widowed, divorced or separated, being a current or former smoker, being overweight or obese, and having health insurance coverage. On the contrary, Hispanic and male were the only two factors having a significant OR less than 1. No significant findings were obtained for state and urban/rural area factors.

The smoothing functions in Fig. 3 display a monotone decline of log OR with increasing age. Thus, the OR decreased with as much as $40 \%$ over the age spectrum investigated, i.e. from $0.94(=\exp [0.75-0.81]$; 95\% CI: $0.93-0.96)$ for the 19-year olds to 0.16 (=exp[-1.01-0.81]; 95\% CI: 0.12-0.22) for the 99-year level and the strongest decline took place before the 30-year mark. Moreover, the time smoother showed a monotone elevation trend from 2000 to 2008, but a clear break in the degree of increase occurred in 2005. The curve reached its maximum OR in late 2008 at 1.29 (=exp[0.07-(-0.19)]; 95\% CI: 1.26-1.31), then turned into a slight decline from 2009 to 2011.

Fig. 4 displays the spatial influence on asthma, where counties with high odds for asthma were found more likely to be located around the Bay Area in California with the odds decreasing towards Arizona, New Mexico and Texas. The odds range among the 360 counties varied from 0.70 to 1.54 . The significance map demonstrates that counties in California and Arizona were more likely to have OR values significantly greater than 1 . On the contrary, counties in Texas along with the Gulf of Mexico and around larger cities such as Dallas, Houston and San Antonio had OR values significantly less than 1 . All in all, there were $43(11.9 \%)$ high-risk counties, 66 (18.3\%) lowrisk ones and 251 (69.7\%) non-significant for asthma prevalence.

The overall spatial variance in the south-western states was 0.033 (95\% CI: 0.020-0.053), which shows that the risk of asthma prevalence at the county level is on average about $19.9 \%$ (= [exp $(\sqrt{ } 0.033)-1] \times 100 \%$; $95 \%$ CI: $15.35-25.81)$ higher or lower than the overall asthma prevalence. After considering the impact of risk factors on the change of geographical disparity, geographical disparities decreased from $-0.61 \%$ to $-0.01 \%$ when removing the following seven risk factors: employment, education, state, marital status, income, smoking status and age. This implies that geographical disparities may exist in these predictors as including them in the model. 

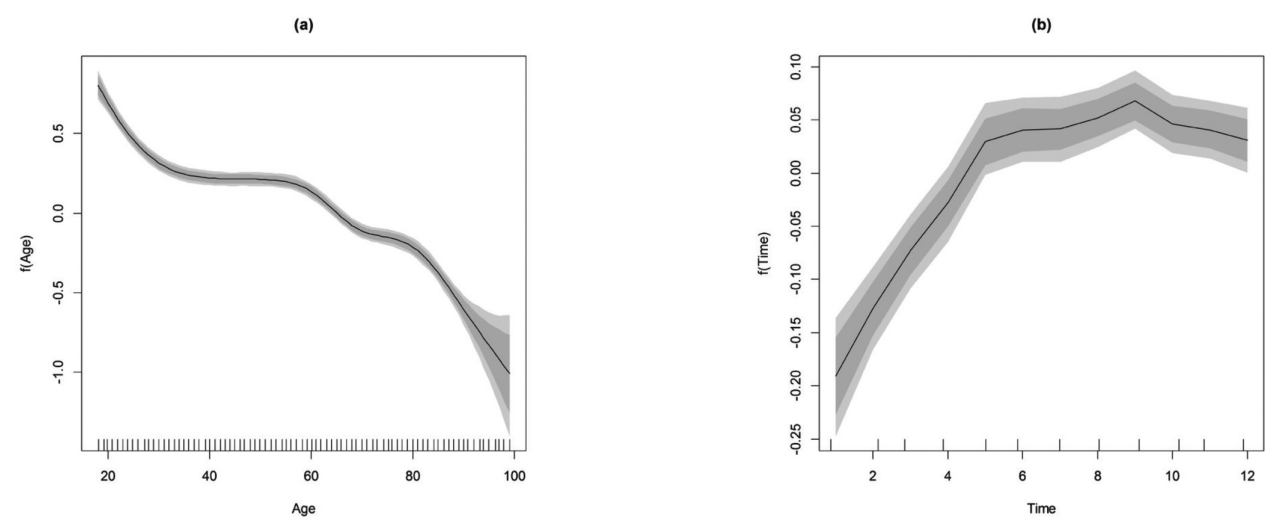

Fig. 3. Smoothing functions for (a) age and (b) time. The dark grey area represents $80 \%$ credible interval (CI) and the light grey area $95 \%$ CI.

\section{Discussion}

The findings of this study have contributed to the known geographical differences of asthma prevalence across USA (CDC, 2010) and added to the body of knowledge on asthma prevalence in a number of ways. First, a variation of spatial pattern for asthma was found to exist in the south-western states. Second, the county-level analysis determined that high-risk counties were more likely to be clustered in California, while Texas had more low-risk counties, especially in the south and south-eastern counties of the state. Third, geographical disparities were successfully quantified. The average, county-level, asthma prevalence varied with $19.9 \%$ from the overall prevalence. Importantly, the study was able to visualise spatial heterogeneity in asthma in these states, to monitor counties with high risk of asthma and to quantify geographical disparity, explaining the level of variation of asthma risk.
In 2011, the average of lifetime and current asthma prevalence in USA was $13.4 \%$ and $8.8 \%$, respectively. The range of prevalence in the south-western states is from $12.3 \%$ (Texas) to $15.3 \%$ (New Mexico) for lifetime asthma and from $7.4 \%$ (Texas) to $10.0 \%$ (New Mexico) for current asthma, showing a diverse distribution across the national average (CDC, 2011a). Possible reasons of this diversity have been proposed in previous studies and may include traffic volume, proximity to freeways, rural areas, low-quality housing and polluted environment (Malo and Chan-Yeung, 2001; Krieger et al., 2000, 2010; Halterman et al., 2008; Deger et al., 2010). The demographic make-up and socioeconomic disadvantages may also account for some of this variation. However, this study is first to quantify GIS data over a very large area on asthma. The US south-west of USA experiences pressing health and social conditions, higher rates of uninsured people, inequitable health conditions and greater poverty,
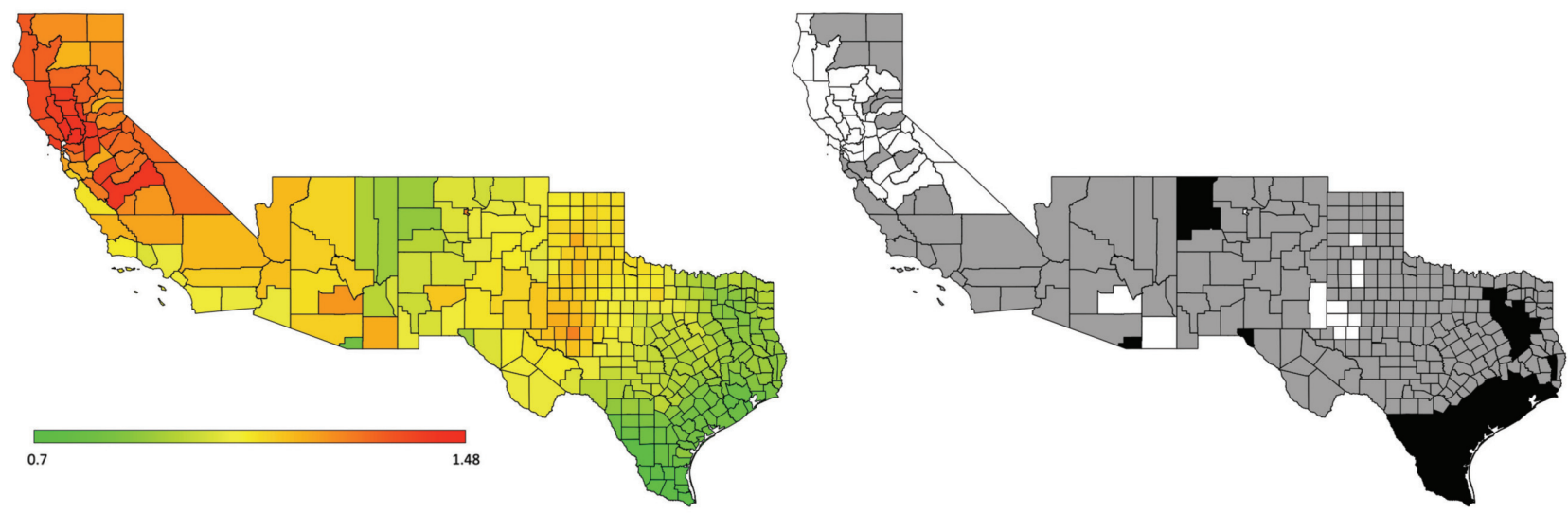

Fig. 4. Map of odds ratios for asthma calculated by the exponential spatial function (left) and the corresponding significance map (right) in the the south-west of USA, 2000-2011. Red represents higher odds and green lower odds. The corresponding significance map indicates high-risk in white and low-risk in black with counties carrying non-significant risk in grey. 
which can potentially result in dramatically high asthma prevalence (US-Mexico Border Health Commission, 2013). The map in Fig. 4 shows that most counties in Texas have generally lower OR values, while California counties are more likely to have higher ones, which demonstrates that the remaining variation of asthma could be explained by location after controlling for other possible confounding factors. This result not only attributes to location, but could also be regarded as a comprehensive confounder containing other risk factors not collected in the BRFSS database, such as indoor and outdoor air quality (Delfino, 2002), healthcare utilisation (Vollmer et al., 2002) or intervention (Baren et al., 2001).

The term "disparity" is often used in relation to ethnicity, gender, etc. but geographical location also contributes to an individual's ability to health access. A goal of Healthy People 2010 proposed by U.S. Department of Health and Human Services (DHHS) was to reduce geographical disparities (DHHS, 2010), which has been well researched for diseases other than asthma (Schootman et al., 2010, 2011; Chien et al., 2013a). However, asthma research has been less focused on this issue, or geographically constrained to small areas with limited sample sizes. For example, an asthma screening to characterise the spatial variation of childhood asthma prevalence by neighbourhood, conducted among children attending 105 Chicago schools, concluded that asthma prevalence in predominantly Black neighbourhoods was higher than in predominantly White and Hispanic/Latino ones (Gupta et al., 2008). A community in Jefferson county with 32 ZIP code areas identified several aggregation patterns of asthma rates in the distribution of poverty, African-American proportion of the population and educational attainment (Jones et al., 2004). The rural-urban difference in children's hospitalizations due to asthma was also predicted in Texas by the use of socio-spatial ZIP code level predictors, suggesting that the existence of interactions between local and social factors created vulnerability to hospitalisation in marginalised areas (Grineski, 2009). An asthma surveillance technique was developed by applying density estimation mapping to provide further information for health care professionals in Alameda county, California, concluding that high-poverty communities had higher rates of emergency room visits due to asthma than low-poverty communities (English et al., 2006). In another report regarding the demographic risk factors for asthma hospitalisations in urban versus rural areas of Mississippi, higher odds of multiple asthma discharges were reported for rural residents, after controlling for race, sex, age and income (Roy et al., 2010). Although results from these previous studies can be conservatively explained by location restrictions, they still reveal a meaningful link between geography and asthma. Indeed, they led this study to apply advanced approached in a broader area.

It was determined that California has a higher number of high-risk counties for asthma than the other three states in this study, an observation that deserves further comment with respect to locality. Adults with asthma in California selectively avoid cigarette smoking (Eisner et al., 2001), while racial and ethnic minorities bear a disproportionately large part of the burden of asthma, and have also higher access to care and exposure to indoor environment triggers (Meng et al., 2007). These disparities are likely caused by a combination of factors: access to primary care, SES, zoning and transportation patterns, housing quality and geographical variation. The area's long history of environmental pollution is of particular concern, including waterfront industry, trucking and traffic pollution (Barrett and Marcus, 2013; Murphy, 2013), possible causes that might add to the spatial vulnerability for other generally quantifying unknown risk factors contributing to asthma prevalence. These results from a complex, spatio-temporal analysis demonstrates the need for further investigations for discovering unknown risk factors of the high asthma risk in California.

No other studies have investigated the level of geographical disparity in an area as large as the one investigated here. Although it is unknown if the estimated geographical disparity percentage reported by us would be considered as severe, this study demonstrates that employment is more likely the main factor leading to the increased geographical disparity. The association between employment and asthma has been well investigated; specifically, researchers tend to distinguish occupational asthma from general asthma. Patients with occupational asthma may completely or partially stop work (Blanc et al., 1996), so the diagnosis of occupational asthma elevates the risk of becoming unemployed (Ameille et al., 1997). Employment is generally discussed with regard to asthma, but it is not known whether it causes geographical disparities of asthma. Our finding quantifies the geographical disparities for asthma prevalence, reveals employment as major factor and suggests reducing such disparities by employment-related interventions, such as asthma disease management designed for unemployed patients aimed at improving their health. 
This study observed the greatest OR in obesity compared to other predictors. Obese individuals comprise $34 \%$ of the adult population $\geq 20$ years in USA. Obese adults are more likely to report poor asthma-specific quality of life, poor asthma control and an increase in asthma-related hospitalizations (Mosen et al., 2008). Nonetheless, the association between obesity and asthma is complex and difficult to evaluate when considering the possible influence of genetics, immune system modification and mechanical mechanisms (Brisbon et al., 2005). Obesity is also related to decreased physical activity and environmental structures that inhibit or encourage opportunities for physical activity. However, changes with regard to those factors could impact obesity prevalence, and therefore directly reduce the severity of asthma (Redd and Mokdad, 2002). In addition, it must be admitted that BRFSS data do not provide a consistent measurement of physical activity in each year, causing difficulties to advancing investigations regarding this association. Although the evidence shows an association between asthma and obesity, the exact nature of this association remains unclear and is also beyond the scope of this study.

A major strength of this study was the implementation of the STAR modelling approach. In particular, using a spatial function in the STAR model was an innovation in epidemiological asthma research because the spatial function not only controls for potential spatial autocorrelation, but also quantifies geographical disparities of asthma in order to realise the diversity of spatial pattern of asthma risk. Moreover, the flexibility of functionalities in the STAR model facilitates both linear (e.g. race and sex) and nonlinear relationships (e.g. age) to asthma. The spatial function can even adopt the 2-dimensional smoothing function or kriging to deal with pointbased geographical data, e.g. coordinate approach (Fahrmeir and Kneib, 2011). Furthermore, the Bayesian inference of the STAR model provides the possibility of accounting for parameter uncertainty in the data analysis (Chien et al., 2012). Even though this is the first application of the STAR model in asthma research, this statistical approach has been successfully used in other fields, such as cancer (Chien et al., 2013b), respiratory disease (Chien et al., 2012; Yu et al., 2012), malnutrition (Khatab, 2010; Kandala et al., 2011), or suicide (Álvaro-Meca et al., 2013). Hence, it is expected that this methodology, as used in this study, will be later expanded to more location-related aspects in asthma research.

Potential limitations of this study should be men- tioned. First, since BRFSS, the main data source used here, does not include subjects younger than 18 years of age. Therefore, children, who usually have greater asthma prevalence compared to adults, were not included. In addition, the questionnaire answers were self-reported without advanced screening or including clinical measures. Second, other important risk factors, such as alcohol use and physical exercise, were excluded because of inconsistency in temporal data capturing. Third, geographical disparity may be different in different geographical units, such as ZIP codes or census tracts. Researchers should take these limitations into consideration when interpreting and comparing the study results.

\section{Conclusion}

Spatio-temporal analyses provide an efficient and meaningful way to use and interpret existing surveillance data for asthma. It also provides visualised information to develop and deliver future interventions in targeted areas and populations. This study clearly identified that the high-risk areas for asthma were likely to be concentrated in California around the Bay Area after adjusting for individual characteristics, SES and health-related behaviour. Further research is needed to understand the complex interaction between geographical location and other risk factors of asthma.

\section{References}

Adebayo SB, Fahrmeir L, 2005. Analysing child mortality in Nigeria with geoadditive discrete-time survival models. Stat Med 24, 709-728.

Álvaro-Meca A, Kneib T, Gil-Prieto R, Gil de Miguel A, 2013. Epidemiology of suicide in Spain, 1981-2008: a spatiotemporal analysis. Public Health 127, 380-385.

Ameille J, Pairon JC, Bayeux MC, Brochard P, Choudat D, Conso F, Devienne A, Garnier R, Iwatsubo Y, 1997. Consequences of occupational asthma on employment and financial status: a follow-up study. Eur Respir J 10, 55-58.

Arif AA, Delclos GL, Lee ES, Tortolero SR, Whitehead LW, 2003. Prevalence and risk factors of asthma and wheezing among US adults: an analysis of the NHANES III data. Eur Respir J 21, 827-833.

ATSDR, 2010. Environmental triggers of asthma. Available at: http://www.atsdr.cdc.gov/csem/csem.asp? csem $=18 \&$ po $=6$ (accessed on September 2013).

Baren JM, Shofer FS, Ivey B, Reinhard S, DeGaus J, Stahmer SA, Panettieri R, Hollander JE, 2001. A randomised, controlled trial of a simple emergency department intervention to improve the rate of primary care follow-up for patients with 
acute asthma exacerbations. Ann Emerg Med 38, 115-122.

Barrett M, Marcus J, 2013. The geography of asthma risk. Available at: http://www.huffingtonpost.com/meredith-barrett-phd/geography-of-asthma-risk_b_2910104.html (accessed on November 2013).

Besag J, York J, Mollié A, 1991. Bayesian image restoration, with two applications in spatial statistics. Ann Inst Stat Math 43, 1-20.

Blanc PD, Cisternas M, Smith S, Yelin EH, 1996. Asthma, employment status, and disability among adults treated by pulmonary and allergy specialist. Chest 109, 688-696.

Brezger A, Lang S, 2006. Generalized structured additive regression based on Bayesian P-splines. Comput Stat Data Anal 50, 967-991.

Brisbon N, Plumb J, Brawer R, Paxman D, 2005. The asthma and obesity epidemics: the role played by the built environment - a public health perspective. J Allergy Clin Immunol 115, 1024-1028.

CDC, 2004. Health disparities experienced by Hispanics United States. MMWR Morb Mortal Wkly Rep 53, 935-937. CDC, 2010. Adult asthma data: prevalence tables and maps. Available at: http://www.cdc.gov/asthma/brfss/2010/lifetime/ tableL1.htm (accessed on September 2013).

CDC, 2011a. Adult asthma data: prevalence tables and maps. Available at: http://www.cdc.gov/asthma/brfss/2011/brfssdata.htm (accessed on September 2013).

CDC, 2011b. Asthma state profiles. Available at: http://www.cdc.gov/asthma/stateprofiles.htm (accessed on September 2013).

CDC, 2012. Asthma's impact on the nation. Available at: http://www.cdc.gov/asthma/impacts_nation/default.htm (accessed on October 2013).

CDC, 2013. Hispanic or Latino populations. Available at: http://www.cdc.gov/minorityhealth/populations/REMP/hispanic.html (accessed on September 2013).

Chien LC, Yang CH, Yu HL, 2012. Estimated effects of Asian dust storms on spatiotemporal distributions of clinic visits for respiratory diseases in Taipei children (Taiwan). Environ Health Perspect 120, 1215-1220.

Chien LC, Yu HL, Scootman M, 2013a. Efficient mapping and geographical disparities in breast cancer mortality at the county-level by race and age in the U.S. Spat Spatiotemporal Epidemiol 5, 27-37.

Chien LC, Schootman M, Pruitt S, 2013b. The modifying effect of patient location on stage-specific survival following colorectal cancer using geosurvival models. Cancer Causes Control 24, 473-484.

Deger L, Plante C, Goudreau S, Smargiassi A, Perron Stephane, Thivierge RL, Jacques L, 2010. Home environmental factors associated with poor asthma control in Montreal children: a population-based study. J Asthma 47, 513-520.

Delfino RJ, 2002. Epidemiologic evidence for asthma and expo- sure to air toxics: linkages between occupational, indoor, and community air pollution research. Environ Health Perspect 110, 573-589.

DHHS, 2010. Healthy people 2010. Available at: http://www.healthypeople.gov/2010/default.htm (accessed on April 2014).

Eisner MD, Yelin EH, Trupin L, Blanc PD, 2001. Asthma and smoking status in a population-based study of California adults. Public Health Rep 116, 148-157.

English PB, Roberts EM, Wong M, Wolff C, Valdez S, Van den Eeden SK, Ray GT, 2006. Peer reviewed: progress in pediatric asthma surveillance II: geospatial patterns of asthma in Alameda county, California. Prev Chronic Dis 3, A92.

Fahrmeir L, Kneib T, 2011. Bayesian smoothing and regression for longitudinal, spatial and event history data. New York: Oxford University Press.

Fahrmeir L, Lang S, 2001. Bayesian inference for generalized additive mixed models based on Markov random field priors. J R Stat Soc Ser C Appl Stat 50, 201-220.

Gamerman D, 1997. Sampling from the posterior distribution in generalized linear mixed models. Stat Comput 7, 57-68.

Grineski SE, 2009. Predicting children's asthma hospitalizations: rural and urban differences in Texas. Rural Sociol 74, 201-219.

Gupta RS, Zhang X, Sharp LK, Shannon JJ, Weiss KB, 2008. Geographical variability in childhood asthma prevalence in Chicago. J Allergy Clin Immunol 121, 639-645.

Halterman JS, Montes G, Shone LP, Szilagyi PG, 2008. The impact of health insurance gaps on access to care among children with asthma in the United States. Ambul Pediatr 8, 43-49. Ingram DD, Franco SJ, 2012. NCHS urban-rural classification scheme for counties. Vital Health Stat 154, 1.

Jones VF, Lawson P, Robson G, Buchanan B, Aldrich T, 2004. The use of spatial statistics to identify asthma risk factors in an urban community. Pediatr Asthma Allergy Immunol 17, 3-13.

Kamble S, Bharmal M, 2009. Incremental direct expenditure of treating asthma in the United States. J Asthma 46, 73-80.

Kandala NB, Brodish P, Buckner B, Foster S, Madise N, 2011. Millennium development goal 6 and HIV infection in Zambia: what can we learn from successive household surveys? AIDS 25, 95-106.

Kandala NB, Madungu TP, Emina JBO, Nzita KPD, Cappuccio FP, 2011. Malnutrition among children under the age of five in the Democratic Republic of Congo (DRC): does geographical location matter? BMC Public Health 11, 261.

Kazembe LN, Mpeketula PM, 2010. Quantifying spatial disparities in neonatal mortality using a structured additive regression model. PLoS One 5, e1118.

Khatab K, 2010. Childhood mulnutrition in Egypt using geoadditive gaussian and latent variable models. Am J Trop Med Hyg 82, 653-663.

Kindermann R, Snell JL, 1980. Markov random fields and their 
applications. Contemporary Mathematics. Volume 1. Providence, RI: American Mathematical Society.

Krieger J, Jacobs DE, Ashley PJ, Baeder A, Chew GL, Dearborn D, Hynes HP, Miller JD, Morley R, Rabito F, Zeldin DC, 2010. Housing interventions and control of asthma-related indoor biologic agents: a review of the evidence. J Public Health Manag Pract 16, S11-S20.

Krieger JW, Takaro TK, Stout J, 2000. Asthma and the home environment of low-income urban children: preliminary findings from the Seattle-King county healthy homes project. J Urban Health 77, 50-67.

Lang S, Brezger A, 2004. Bayesian P-Splines. J Comput Graph Stat, 13, 183-212.

Malo JL, Chan-Yeung M, 2001. Occupational asthma. J Allergy Clin Immunol 108, 317-328.

McEntee J, Ogneva-Himmelberger Y, 2008. Diesel particulate matter, lung cancer, and asthma incidences along major traffic corridors in MA, USA: a GIS analysis. Health Place 14, 817 828.

Mead H, Cartwright-Smith L, Jones K, Ramos C, Woods K, Siegel B, 2008. Racial and ethnic disparities in US health care: a chartbook. New York: The Commonwealth Fund.

Meng YY, Babey SH, Hastert TA, Brown ER, 2007. California's racial and ethnic minorities more adversely affected by asthma. Policy Brief UCLA Cent Health Policy Res Feb (PB20073), 1-7.

Mosen DM, Schatz M, Magid DJ, Camargo Jr CA, 2008. The relationship between obesity and asthma severity and control in adults. J Allergy Clin Immunol 122, 507-511.

Murphy K, 2013. Pollution takes heavy toll on Bay Area child with asthma. Inside Bay Area. Available at: http://www.insidebayarea.com/breaking-news/ci_22553890/pollution-takesheavy-toll-bay-area-children-asthma (accessed on November 2013)

Musio M, Sauleau EA, Buemi A, 2010. Bayesian semi-parametric ZIP models with space-time interactions: an application to cancer registry data. Math Med Biol 27, 181-194.

Oyana TJ, Lwebuga-Mukasa JS, 2004. Spatial relationships among asthma prevalenc, health care utilization, and pollution sources in neighborhoods of Buffalo, New York. J Environ Health 66, 25-37.

PubMed Health, 2013. Asthma. Available at: http://www.ncbi.nlm.nih.gov/pubmedhealth/PMH000
1196/ (accessed on April 2014).

QGIS Development Team, 2011. QGIS Geographical Information System Developers Manual. Open Source Geospatial Foundation Project.

Redd SC, Mokdad AH, 2002. Obesity and asthma - new perspectives, research needs, and implications for control programs. Am J Epidemiol 155, 198-200.

Roy SR, McGinty EE, Hayes SC, Zhang L, 2010. Regional and racial disparities in asthma hospitalizations in Mississippi. J Allergy Clin Immunol 25, 636-642.

Sahsuvaroglu T, Jerrett M, Sears MR, McConnell R, Finkelstein N, Arain A, Newbold B, Burnett R, 2009. Spatial analysis of air pollution and childhood asthma in Hamilton Canada: comparing exposure methods in sensitive subgroups. Environ Health 8, 14.

SAS Institute, 2009. SAS OnlineDoc, NC: SAS Institute Inc.

Schootman M, Lian M, Deshpande AD, Baker EA, Pruitt SL, Jeffe DB, 2010. Temporal trends in geographical disparities in small-area breast cancer incidence and mortality, 1988 to 2005. Cancer Epidemiol Biomarkers Prev 19, 1122-1131.

Schootman M, Lian M, Deshpande AD, McQueen A, Pruitt SL, Jeffe DB, 2011. Temporal trends in geographical disparities in small-area-level colorectal cancer incidence and mortality in the United States. Cancer Causes Control 22, 1173-1181.

Spiegelhalter DJ, Best NG, Carlin BP, Van Der Linde A, 2002. Bayesian measures of model complexity and fit. J Roy Stat Soc B 64, 583-639.

Umlauf N, Kneib T, Heinzl F, Lang S, Zeileis A, 2013. R2BayesX: Estimate structured additive regression models with BayesX. R package version 0.1-2.

US-Mexico Border Health Commission, 2013, Border Region. Available at: http://www.borderhealth.org/border_region.php (accessed on September 2013).

USCB, 2013. Cartographic Boundary Files. Available at: http://www.census.gov/geo/maps-data/data/tiger-cart-boundary.html (accessed on September 2013).

Vollmer WM, Markson LE, O’Connor E, 2002. Association of asthma control with health care utilization: a prospective evaluation. Am J Respir Crit Care Med 165, 195-199.

Yu HL, Chien LC, Yang CH, 2012. Asian dust storm elevates childern's respiratory health risks: a spatiotemporal analysis of children's clinic visits across Taipei (Taiwan). PLoS One 7, e41317. 


\section{Appendix}

To develop Bayesian estimates for our STAR model, it is assumed that all priors of intercept and slope are non-informative uniform priors (Musio et al., 2010). Two smoothing functions $\mathrm{f}($ Age $)$ and $\mathrm{f}(t)$ have a fundamental assumption of P-spline in that a smoothing function, symbolised by $\mathrm{f}(\mathrm{x})$ of a covariate $\mathrm{x}$, can be decomposed by a number of knots $\mathrm{K}$ and several pieces of B-splines:

$$
\mathrm{f}(\mathrm{x})=\sum_{k=1}^{K} \alpha_{k} \mathrm{~B}_{k}(\mathrm{x}) .
$$

We used quadratic B-splines and 20 knots to provide enough flexibility and sufficient smoothness of the two fitted curves. We also used a second-order randomwalk prior $\mathrm{a}_{k}=2 \mathrm{a}_{k-1}-\mathrm{a}_{k-2}+\mathrm{u}_{k}$ for the B-spline coefficients, where $\left(\mathrm{a}_{k-1}, \mathrm{a}_{k-2}\right)$ have diffuse priors, and $\mathrm{u}_{k}$ is a normal distribution with mean 0 and variance. In particular, the unknown variance parameter $\tau^{2}$ controls the amount of smoothness, and is also estimated from the data (Lang and Brezger, 2004).

In a process similar to that used with smoothing functions, the heterogeneity due to spatial dependence was addressed by the spatial function $f_{\text {spat }}(j)$. Among diverse types of spatial function in the STAR model, Markov random fields (MRF) (Kindermann and Sneel, 1980; Besag et al., 1991) are usually applied with the use of boundary data. The MRF is achieved by assuming a conditional autoregressive prior for spatial function as

$$
N\left(\sum_{\substack{j \in \omega_{i} \\ j \neq j^{\prime}}} \frac{\mathrm{f}_{\mathrm{spat}}\left(j^{\prime}\right)}{N_{j}}, \frac{\sigma_{j}^{2}}{N_{j}}\right),
$$

where county $j^{\prime}$ is a neighbour county adjacent to county $j, \omega_{j}$ a set of neighbour counties around county $j$ and $\mathrm{N}_{j}$ the number of neighbours in $\omega_{i}$. The unknown variance parameter $\sigma_{i}^{2}$ follows an inverse Gamma distribution IG $(a, b)$ with two assigned hyperparameters $a=0.001$ and $b=0.001$ under a fully Bayesian inference. Again, the variance $\sigma_{j}^{2}$ controls the degree of smoothness of the spatial function.

The methodology of the STAR model was developed upon an empirical Bayesian inference with restricted maximum likelihood method and a fully Bayesian inference to build numerical algorithms for the estimating equation. This study adopts the later one using the Markov chain Monte Carlo simulation techniques. This study adopted the later one to fulfil the model fitting, which is carried out by randomly drawing samples from a fully conditional distribution of blocks of parameters given the rest of parameters and data (Brezger and Lang, 2006). Moreover, by initialising the starting value of smoothing parameters as 10 , an iteratively weighted least squares proposal was used to update all smoothing parameters (Gamerman, 1997). We used a total of 25,000 iterations with the first 5,000 burn-ins, and store every $20^{\text {th }}$ sample from the remaining 20,000 samples giving a final sample of 1,000 to construct the posterior distribution of each unknown parameters. Hence, the posterior mean and variance of the posterior distribution can determine parameter's estimation and credible interval. The deviance information criterion developed by Spiegelhalter et al. (2002), a measure of fit and model complexity, was adopted in the STAR model for model diagnostic or model selection. The sampling paths and autocorrelation functions for estimated parameters can be drawn to detect the stability of sampling trace over iterations and the existence of autocorrelation. 